\title{
USE OF WAVEFORMS IN SETTING VENTILATORY PARAMETERS
}

\author{
Asoka Gunaratne \\ Consultant Anaesthetist, Teaching Hospital Karapitiya \\ *Corresponding author: asoka.gunaratne@yahoo.com
}

Key words: pressure, volume, time

With the advent of new technology ventilators in the intensive care units have become very sophisticated with a lot of clinical material depicted in the form of graphics. The present day intensivist needs to have a very good understanding of these parameters if the patient is to benefit.

Waveforms are graphical representations of data collected by the ventilator either integrated with changes in time (as in Pressure-time, Flow-Time or Volume-Time curves) or with one another (as in pressure-Volume of Flow-Volume loops).

Waveforms offer the user a "window" to visualize what is happening in the patient's lungs in realtime in the form of pictures. The digital values generated and displayed by the ventilator generally lag by at least one breath and in some case 4 to 8 breaths.

Waveforms analysis can also help the clinician detect circuit and airway leaks, estimate imposed ventilatory work, and aid in assessing the efficacy of bronchodilator therapy.

The two common modes of ventilation are

1. Volume control and

2. Pressure control

\section{Pressure-Time curve (Volume control)}

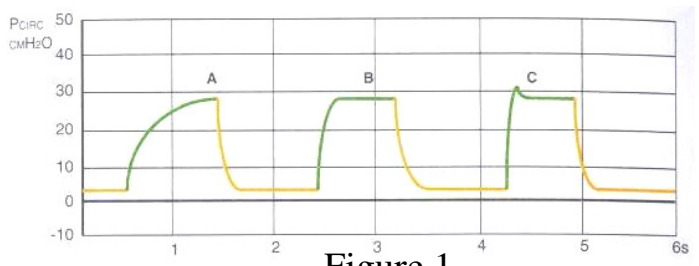

Figure 1
There is gradual rise in pressure (Figure 1, A). If breath is held in inspiration the drop in peak pressure indicate plateau pressure, which indicate alveolar pressure. (Figure 2)

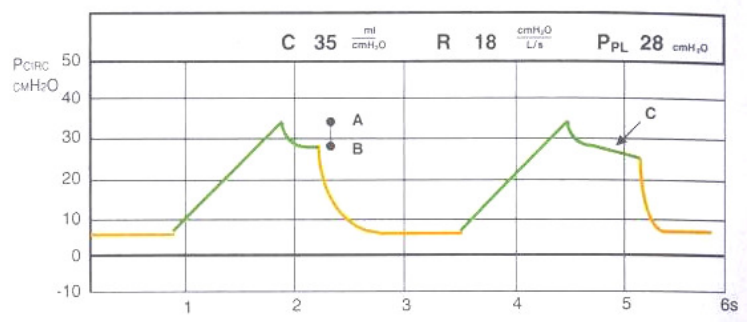

Figure 2

If breath is held in expiration the PEEP rise above the set level will indicate auto PEEP (Figure 3).

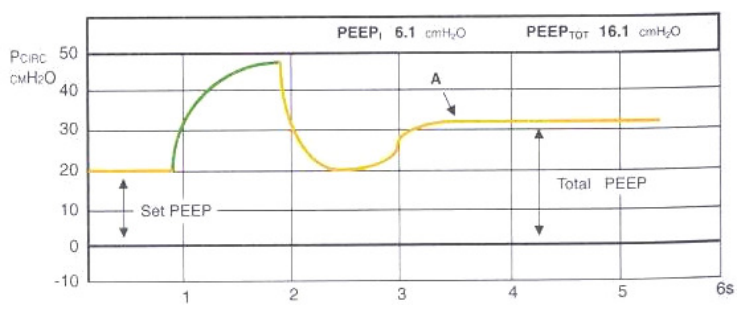

Figure 3

\section{Pressure-Time curve (Pressure control)}

Sudden rise in pressure and maintains it throughout inspiration. Therefore alveolar recruitment is better. However tidal volume will vary with compliance of the lung (Figure 1, B).

\section{Flow-Time curve (Volume control)}

Constant flow through out inspiration (Figure 4). 


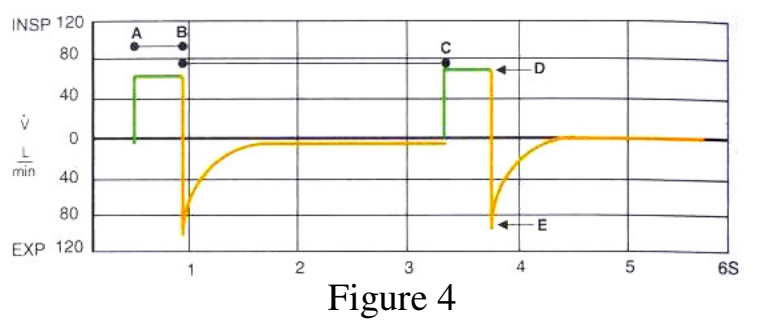

Flow-Time curve (Pressure control) Exponential drop in flow (Figure 5, B).

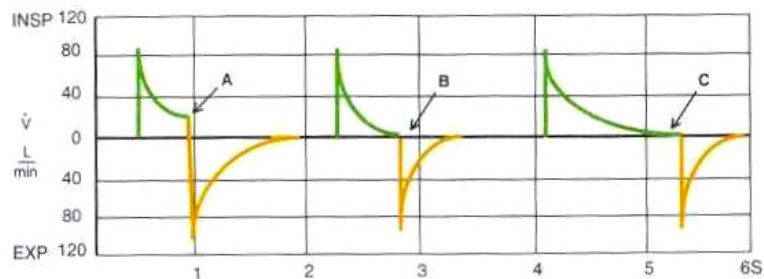

Figure 5

Premature termination of inspiration (Figure 5, A). One can change the I : E ratio to increase the inspiratory time (Figure 5, C).

Premature termination of expiration (Figure 6). This may result in air trapping. One can change the $\mathrm{I}$ : E ratio to increase the expiratory time.

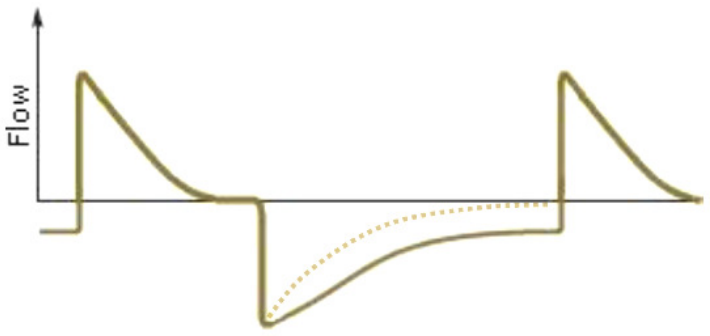

Figure 6

Volume-Time curve

The curve is the same for both volume and pressure control ventilation (Figure 7).

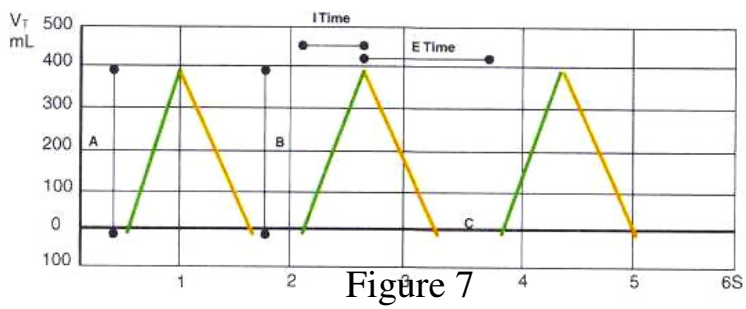

Loss of volume in expiration indicates air leak of air trapping (Figure 8).

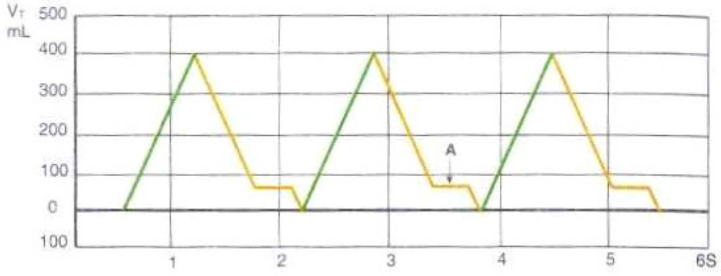

Figure 8

Pressure Volume loop

A left shift indicate increased resistance to expiration and a right shift indicate resistance to inspiration (Figure 9).



A pressure increase without an increase in volume indicates over distention. This might result in barotrauma. One needs to reduce the tidal volume (Figure 10).

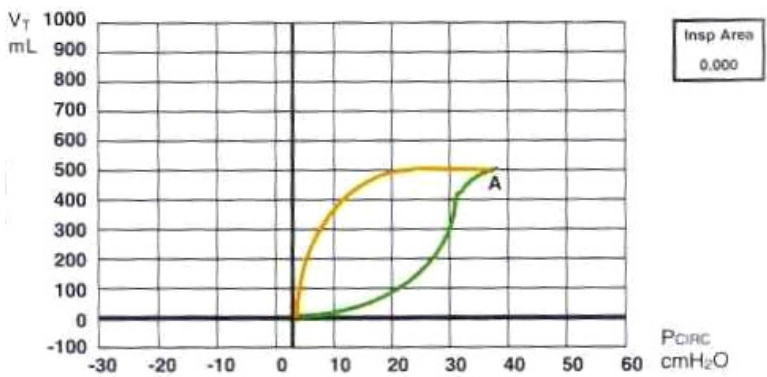

Figure 10

Expiration not returning to base line indicates an air leak or air trapping (Figure 11).

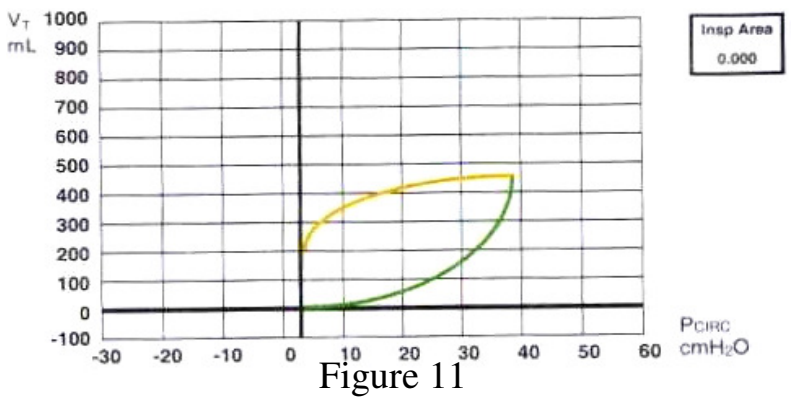


Negative pressure in the pressure axis denotes spontaneous breathing. Higher the area on this side, higher the work needs to be done to trigger the ventilator (Figure 12).

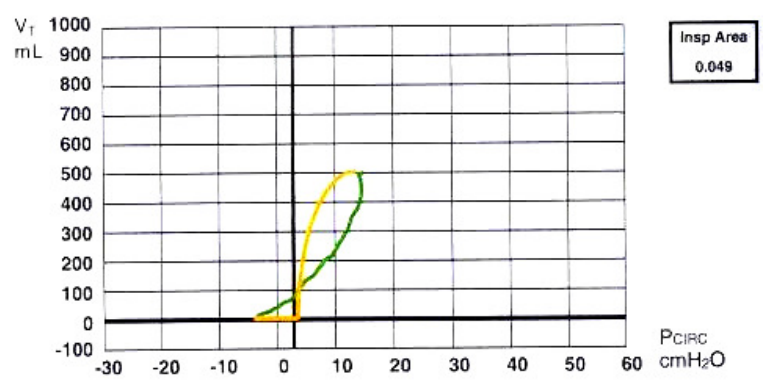

Figure 12

\section{Flow volume loop}

Normal flow volume loop (Figure 13). Scooping indicates increased air way resistance (Figure 14).



Figure 13

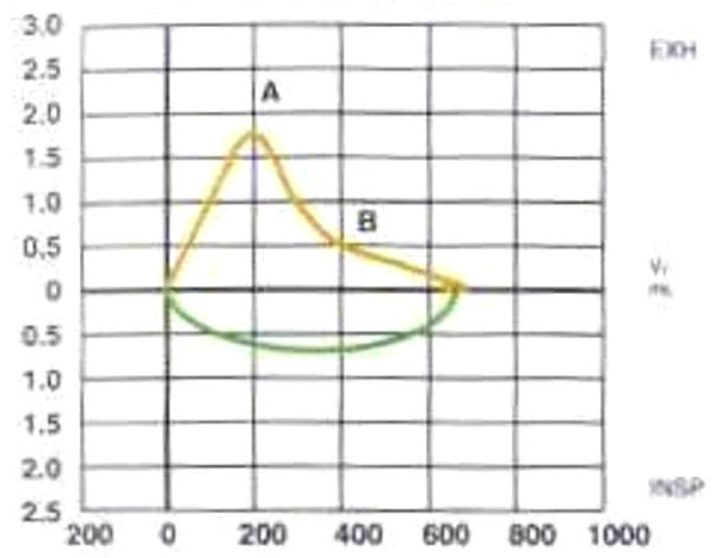

Figure 14

\section{References}

1. Truwit JD, Marini JJ. Evaluation of thoracic mechanics in the ventilated patient. Part 1: primary measurements. Journal of Critical Care 1988; 3: 133-150.

2. Truwit JD, Marini JJ. Evaluation of thoracic mechanics in the ventilated patient. Part 11: applied mechanics. Journal of Critical Care 1988; 3: 199-213.

3. Branson RD, Hess DR. Bed side monitoring of respiratory mechanics. Respiratory Care Equipment. $2^{\text {nd }}$ edition. Philadelphia Lippincott, William \& Wilkins; 1999:303-324.

4. Ranieri VM, Grasso S, Fiore T, Guilani r. Autoend expiratory pressure and dynamic hyperinflation. Clinical Chest Medicine 1996;17(3):379-394

5. Tobin MJ. Respiratory monitoring in the intensive care unit. American Review in Respiratory Disease 1998; 138(6): 1625-1642.

6. Kondili E, Priniankis G, Georgopoulos D. Patient ventilator interaction. British Journal of Anaesthesia 2003; 91(1):106-119.

7. Sassoon CS, Gruer SE. Characteristics of the ventilator pressure and flow-trigger variables. Intensive Care Medicine. 1995; 21(2):159-168.

8. Tobin MJ, Jubran A, Laghi F. Patient Ventilator Interaction. American Journal of Respiratory Critical Care Medicine. 2001; 163(5):1059-1063. 